\title{
Methodological approaches in assessing the effectiveness of the use of feed additives of humic nature in productive livestock
}

\author{
Stepchenko L.M.
}

Dnipro state agrarian and economic university, Dnipro, Ukraine, stepchenko2@gmail.com

\author{
doi: 10.36291/HIT.2019.stepchenko.016
}

The spectrum of biological effects of feed additives and preparations of humic nature in industrial animal husbandry has a multi-vector dependence. At the same time, the selection of humic-containing raw materials (peat, brown coal, leonardite, sapropel, and also the products of the vital activity of worms) in terms of physicochemical, biological, and environmental characteristics can be put in first place. Only after the first stage it is possible to evaluate the biological effect of humic substances on the animal organism. The report gives a retrospective of methodological approaches for the selection of humic feed additives for various types of farm animals as adaptogens, immunomodulators and regulators of metabolic processes of biological production synthesis. In our studies, environmentally friendly peat was used from 3 different deposits of Ukraine, which were selected after analysis of peat samples from 18 deposits using the screening system which we developed for their assessment (Stepchenko L.M., Sedykh N.I. 2011). More than 30 years of experience in this area research allowed us to offer a certain sequence of experiments stages to assess the effectiveness of humic nature feed additives in animal husbandry. 1. Determination of biological characteristics of the studied feed additives and determination of the presence of acute and chronic toxicity. 2. Conducting one or more experiments on laboratory animals in order to determine the dose-effect relationship. 3. Determination in laboratory animals (mice and rats), the level of antioxidant, hepatoprotective and immunomodulating activities of humic nature food additives can also be established by biological markers of indicators of homeostasis. 4. The transition to checking the effectiveness of the use of feed additives for farm animals in an environment of livestock. Initially, 2-3 dosages are used, the effectiveness of which was detected in laboratory animals, taking into account the metabolic rate of the corresponding species of productive animals and taking into account the duration of their use and compatibility with veterinary measures that are carried out in the conditions of the economy. 5. Assessment of the animals' productive qualities, qualitative and quantitative characteristics of biological products. The report will also present methodological approaches to determine the degree of influence of humic nature feed additives on digestion processes, the degree of metabolic restructuring of the liver function, the main indicators of homeostasis, as well as quantitative and qualitative characteristics of the resulting biological products. Experiments on the use of feed additives obtained from peat were carried out on the basis of a research humic substances laboratory named after professor L.A. Christeva of the Dnipro State Agrarian and Economic University and agricultural enterprises of Ukraine. As a result of applying the proposed research approaches, we developed technological schemes for the application of such feed additives as "Huminat", "Hydrogumat" and "Humilid" for broiler chickens, laying hens, ostriches, pheasants, turkeys, pigs of various technological groups, as well as for cattle. 